Artikel Konseptual

\title{
PANTULAN BUDAYA LOKAL “MAKNA FILOSOFIS DAN SIMBOLISME MOTIF BATIK KLASIK" UNTUK PENGUATAN PENDIDIKAN KARAKTER
}

\begin{abstract}
Sariyatun
sari_fkip_uns@yahoo.co.id

Prodi Pendidikan Sejarah FKIP UNS

Abstract. Local wisdom is one of the principles of development and Implementation of Strengthening Character Education (SCE). It is argued that one of the dominant influences of globalization is "cultural imperialism" or "cultural homogeneity," which affects the loss of youth experience and understanding of local cultural diversity. Local wisdom will proactively transform global products into meaningful and appropriate to local social and cultural life. Local wisdom, as the "found tradition" shows that the past culture is not really abandoned even though times have changed. The construction of batik culture has grown in the awareness of society with all its uniqueness. Batik is able to survive across the ages and eventually become an heritage legacy. The dynamic reinterpretation of the core values of philosophical meanings and the symbolism of classical batik motifs is done with the contemporary context for the strengthening of character education.
\end{abstract}

Keywords: culture, philosophy, symbolism, classical batik, and character

\section{PENDAHULUAN}

Abad XXI ditandai dengan enam kecenderungan penting, yaitu ; (a) Berlangsungnya revolusi digital yang semakin luar biasa yang mengubah sendi-sendi kehidupan, kebudayaan, peradaban, dan kemasyarakatan termasuk pendidikan, (b) Integrasi belahan-belahan dunia yang semakin intensif akibat internasionalisasi, globalisasi, hubungan-hubungan multilateral, teknologi komunikasi, dan teknologi transportasi, (c) Berlangsungnya pendataran dunia (the world is flat) sebagai akibat berbagai perubahan mendasar dimensidimensi kehidupan manusia terutama akibat mengglobalnya negara, korporasi, dan individ, (d) Perubahan dunia yang cepat mengakibatkan ruang tampak menyempit, waktu terasa ringkas, dan keusangan segala sesuatu cepat terjadi, (e) Semakin tumbuhnya masyarakat padat pengetahuan (knowledge society), masyarakat informasi (information society), dan masyarakat jaringan (network society) yang membuat pengetahuan, informasi, dan jaringan menjadi modal sangat penting, (f) makin tegasnya fenomena abad kreatif, yang menempatkan kreativitas dan inovasi sebagai modal penting untuk individu, perusahaan, dan masyarakat. (Kemendikbud, Konsep Pedoman Penguatan Pendidikan Karakter untuk Pendidikan Dasar dan Menengah, 2017) 
Menyikapi kondisi tersebut maka, transformasi pendidikan telah menempatkan karakter sebagai dimensi terdalam pendidikan nasional. Pada dasarnya pendidikan bertujuan mengembangkan potensi-potensi intelektual dan karakter peserta didik. Sebagaimana ditandaskan Ki Hajar Dewantara bahwa "Pendidikan adalah daya upaya untuk memajukan bertumbuhnya budi pekerti (kekuatan batin, karakter), pikiran (intelec) dan tubuh anak. Bagian-bagian itu tidak boleh dipisahkan agar kita dapat memajukan kesempurnaan hidup anak-anak kita" ( Dewantara , 1977).

Kearifan Lokal digunakan sebagai salah satu dasar pengembangan dan implementasi penguatan pendidikan karakter. Hal ini didasari adanya pengaruh dominan dari globalisasiyakni "imperialism kultural" atau "homogenitas budaya" (Hannerz, 1990). Proses perubahan global didukung oleh pengetahuan dan mediateknologi akan melahirkan budaya dunia yang lebih homogen, sehingga terkikisnya nilai-nilai asli yang sebelumnya sakral dan menjadi identitas suatu bangsa. Semua itu berakibat hilangnya pengalaman dan pemahaman generasi muda terhadap keragaman budaya lokal sebagai bagian dari jati diri bangsa.

Watson (2004) menekankan pentingnya peran kerarifan lokal yang akan mengubah produk global menjadi bermakna dan sesuai dengan kehidupan sosial budaya setempat. Dengan demikian sistem pendidikan berbasis kearifan lokal secara proaktif, mampu menghadapi tantangan globalisasi. Keseimbangan globalisasi dan kebudayaan lokal dijelaskan dalam buku The Invention of Tradition (1988) suntingan Eric Hobsbawm dan Terence Ranger. Kearifan lokal disebut "the invention of tradition" atau "penemuan tradisi". Dengan demikian yang tampak kemudian adalah kearifan lokal, pengetahuan lokal, indigenous knowledge, dan local genius. Hobsbawm menyatakan bahwa "tradisi yang ditemukan" menunjukkan ketersambungan dengan masa lalu. Masa lalu tidak benarbenar ditinggalkan, meskipun zaman sudah berubah sangat progresif. Warisan budaya itulah yang membuat suatu bangsa merasa mempunyai identitas. Batik klasik merupakan warisan budaya yang mengandung "tuntunan dan tatanan". Kearifan lokal ini merupakan modal sosial dan jawaban kreatif terhadap kondisi zaman, sehingga dapat dipandang sebagai landasan bagi pembentukan jati diri bangsa (Sariyatun, 2012)

Makalah ini akan memaparkan bagaimana nilai-nilai kearifan lokal Batik Klasik (sebagai pantulan Budaya local) dapat digunakan untuk penguatan pendidikan karakter.Pemaknaan ulang terhadap nilai nilai filosofis batik klasik dilakukan dengan menggunakan paradigm Postmodern. 


\section{PEMBAHASAN}

\section{Nilai Budaya Lokal “ Batik Klasik”}

Secara etimologis kebudayaan berasal dari bahasa Sansekerta "budhayah", yaitu bentuk jamak dari budhi yang berarti budi atau akal. Kebudayaan merupakan keseluruhan sistem gagasan, tindakan, hasil karya manusia dalam rangka kehidupan masyarakat yang diperoleh melaui belajar. Menurut Geertz (1992) kebudayaan adalah 'pola dari pengertian-pengertian atau makna yang terjalin secara menyeluruh dalam simbol-simbol yang ditransmisikan secara historis, suatu sistem mengenai konsepsikonsepsi yang diwariskan dalam bentuk-bentuk simbolik. Dengan cara tersebut manusia berkomunikasi, melestarikan dan mengembangkan pengetahuan dan sikap mereka terhadap kehidupan. Peninggalan budaya yang eksis kemudian menjadi warisan budaya.

Batik merupakan salah satu warisan budaya dan konstruksi budaya batik telah tumbuh dalam kesadaran masyarakat dengan segala kekhasan yang dimiliki. Batik mampu bertahan melintasi zaman dan akhirnya menjadi warisan pusaka. Ada dua hal yang perlu dicermati menurut Kasiyan (1980), yakni pertama pengkritisan atas dimensi sosiologis yakni bagaimana budaya batik dipahami dalam kesadaran dalam lingkungan masyarakat kontemporer. Kedua, pengkritisan dari dimensi akademis untuk mencermati bagaimana sesungguhnya nilai-nilai filosofis batik mendapatkan ruang concern sebagai disiplin kajian. Perspektif pada dimensi akademis atas batik menjadi urgent, karena dimensi edukasi tetap merupakan salah satu pilar bagi penguatan jati bangsa. Dalam konteks ini perlu diciptakan realitas baru (dekontruksi) terhadap nilai-nilai yang bersumber dari motif batik klasik sebagai penguatan pendidikan karakter.

Keindahan pola hias batik dapat dilihat dari keindahan visual dan keindahan filosofis. Menurut Soedardjo (1990), keindahan visual disebut sebagai keindahan estetika dapat dilihat dari motif yang tepat dalam bidang dan tata warna yang harmonis. Keindahan filosofis atau keindahan jiwa, yaitu rasa indah yang diperoleh dari susunan arti lambang yang membuat gambar sesuai dengan paham yang dimengerti. Keindahan ini merupakan perpaduan antara motif dan warna yang menggambarkan pegangan hidup pada waktu itu, karena aspek-aspek kehidupan manusia sedikit banyak sudah terlukiskan dalam ornamen motif batik.

Simbolisme motif batik klasik merupakan kenyataan dari gejala "superorganik, yaitu realitas yang divisualkan dalam berkesenian. Menurut Suzanne K. Lenger sebagai bentuk "virtualitas" ialah sesuatu yang ada tetapi tidak dapat diraba hanya dapat dirasakan keberadaannya.Tanda lahiriah secara teknik dapat ditransformasikan ke dalam beberapa jenis motif batik. Dengan demikian pola hias batik di samping mempunyai 
bentuk dan susunan yang khusus, juga memiliki makna simbolis. Keindahan pola hias batik dapat dilihat dari keindahan visual dan keindahan filosofis.

Makna hanya dapat dipahami melalui perantara sebuah simbol yang menterjemahkan pengetahuan menjadi nilai dan menterjemahkan seperangkat nilai menjadi sistem pengetahuan (Kleden, 1998). Simbol pada umumnya bermakna "piwulang atau pameling". Bastomi (1992), menjelakan lambang dalam budaya Jawa merupakan pertalian budi pekerti manusia dalam konteks kehidupan, merupakan acuan untuk berperilaku dan berfungsi sebagai petunjuk yang memberi arah terhadap pengalaman hidup manusia.

Setiap penciptaan motif batik selalu memiliki makna simbolis berdasarkan falsafah Jawa, karena itu pemakaian motif didasarkan pada dua hal, yakni (1) kedudukan sosial seseorang di dalam masyarakat, (2) pada kesempatan atau peristiwa apa batik dipergunakan tergantung dari makna dan harapan yang terkandung pada ragam hias batik tersebut. Hal ini menjadikan batik klasik mengandung tuntunan dan tatanan. Sebagian idiom makna simbolis motif-motif batik klasik mempunyai kandungan muatan kearifan lokal dan dianggap dapat melampui jamannya. Sebagai contoh adalah motif batik Semen, Truntum, dan Sidoluhur. Pemakaian motif batik Klasik berkaitan dengan hal-hal yang sifatnya transendental atau berlatar belakang magis, dan mengandung tuntunan, Sebagai contoh larangan bagi pengantin tidak memakai kain batik motif Parang Rusak dimaknai dapat mengakibatkan rusaknya tali perkawinan atau perceraian.

Keberadaan batik klasik sebagai tuntunan dan tatanan dibakukan oleh aturan yang dikeluarkan dari Kraton Surakarta yaitu pada Tahun 1769 oleh Paku Buwono III (17491788), sebagai berikut:

"Anadene arupa jajarit kang kalebu ing larangan ingsun: batik sawat lan batik parang rusak, batik cumangkiri kang calacap modang, bangun tulak, lenga teleng, daragem, lan tumpal. Anadene batik cumangkiri ingkang acalacap lung-lungan utawa kekembangan, ingkang ingsun kawenangken anganggoha papatih ingsun, lan sentaningsun kawulaningsun wedana".

“Adapun rupa jarit yang termasuk larangan Saya( Sunan ) : batik sawat dan batik parang rusak, batik cumangkiri yang berupa motif modang bangun tulak, lenga teleng, daragem, dan tumpal. Adapun batik cumangkiri yang berupa motif lung-lungan atau kekembangan (bunga), saya ijinkan dipakai oleh patih saya, dan keluarga bangsawan, abdi dalem wedana (Sariyatun, 2013).

Dalam proses integrasi tatanan global, kebudayaan tidak lagi terikat oleh batasbatas fisik atau ikatan ruang yang deterministik (Appadurrai, 1994; Fetherstone, 1996). Kebudayaan menjadi bersifat situasional yang keberadaanya tergantung pada karakter 
kekuasaan dan hubungan yang berubah dari waktu ke waktu. Karena itu pemosian kebudayaan sebagai sistem simbol mengandung persoalan penting sebagai berikut. Pertama, batas batas wilayah ruang budaya yang mempengaruhi pembentukan simbol dan makna yang ditransmisikan secara historis. Kedua,batas batas dari kebudayaan tersebut menentukan konstruksi makna dipengaruhi oleh hubungan kekuasaan yang melibatkan sejumlah factor. Ketiga, pola hubungan kekuasaan tersebut kemudian berdampak pada identitas kelompok dan menentukan cara pandang kelompok. Keempat, identitas yang terbentuk selain ditreima juga menjadi perdebatan dan gugatan yang menunjukan adanya perubahan dalam batas batas kebudayaan.( Irwan Abdullah, 2009).

Dengan demikian, pemaknaan ulang secara dinamis atas core values motif batik klasik perlu dilakukan dengan konteks kekinian bahkan futuristik untuk kepentingan pendidikan. Redefinisi makna filosofis motif batik klasik, dilakukan dengan menggunakan paradigma Postmodern. Postmodernisme adalah suatu pergerakan ide yang menggantikan ide-ide zaman modern (Leahy ,1985: 271). Zaman modern dicirikan dengan pengutamaan rasio, objektivitas, totalitas, strukturalisasi, universalisasi tunggal dan kemajuan sains (Richhard Harland, 2006). Tema besar yang diusung kaum posmodernisme adalah kerangka dekonstruktif atas kuasa ilmu pengetahuan modern yang berbasis rasionalisme, obyektivitas, strukturalis, sistematisasi, totalisasi dan universalisasi. Pauline M. Rosenau, dalam bukunya Postmodernism and Social Sciences (1992), membedakan postmodernisme menjadi dua bentuk. Pertama, postmodernisme sebagai paradigma pemikiran yang menjadi dasar kerangka berpikir dan bertindak penganut postmodernisme misalnya Derrida maupun Foucault. Kedua, postmodernisme sebagai metode analisis kebudayaan.

Dalam tulisan ini, Postmodernisme digunakan sebagai lensa membaca realitas sosial budaya masyarakat. Dekonstruksi juga dapat dipahami sebagai metode membaca teks filsofis yang kemudian unsur-unsur yang dilacaknya akan dibongkar. Dengan dasar dekonstruksi maka pemahaman nilai budaya batik klasik harus dimulai dengan mendefisikan ulang nilai simbolisme dan filosofis motif batik klasik, bukan sebagai kebudayaan generik, tetapi sebagai kebudayaan deferensial yang dinegosiasikan dalam keseluruhan..

Motif batik klasik adalah tanda yang bisa terus diulang dan dibedakan sesuai dengan perspektif pembaca dan penafsirnya. Cara terbaik dalam menggali makna tersembunyi menurut Derrida ini adalah dengan selalu mempertanyakan semua hal dan menempatkannya pada yang baru. Dengan demikian, kita tidak membiarkan diri untuk menerima sistem yang sudah ada (Sumaryono, E. 1999). Dekonstruksi dalam arti yang 
lebih sempit juga dapat dipahami sebagai metode untuk memahami teks, ataupun realitas lalu mengubahnya untuk memperoleh makna yang baru.

Makna budaya bersifat terbuka akan berubah dan berkembang, bukan milik suatu zaman melainkan terus berjalan seiring perkembangan budaya itu sendiri. Makna budaya bukan unvocityabsolut melainkan multiplicity of meaning, karena makna terkait dengan kreativitas manusia (Derrida, 2002). Logika yang digunakan adalah logika unstandard menurut Borghert (1996), logika discovery menurut Muhadjir (1982), atau logika inquiry menurut Conrad (1993)

Batik klasik sebagai hasil budaya elite feodal yakni Kraton, pada awalnya sebagai budaya adiluhung yang berpusat di Vorstenlanden Surakarta dan Jogjakarta, merupakan media hegemoni budaya Kraton terhadap budaya rakyat. Nilai simbolisme dan filosofis yang motif batik klasik sarat akan kekuasaan, didekonstruksi untuk kepentingan penguatan jati diri bangsa melalui pendidikan karakter. Pemaknaan filosofis yang terkandung dalam warisan budaya batik, selama ini tereduksi hanya dalam proses komodifikasi. Kiranya perlu revitalisasi batik sebagai sarana pembangunan karakter bangsa. Sebagai contoh pemilihan motif batik yang berbeda sebagai seragam sekolah merupakan bagian dari penguatan identitas yang berlandaskan pada pemaknaan baru terhadap nilai filosofis batik sebagai media pendidikan karakter di beberapa sekolah di Surakarta.

\section{Pendidikan Karakter}

Karakter adalah ciri khas yang dimiliki oleh suatu benda atau individu. Ciri khas tersebut adalah asli dan mengakar pada kepribadian benda atau individu tersebut, serta yang mendorong bagaimana seorang bertindak, bersikap, berucap, dan merespon sesuatu. Koesoema (2007) menjelaskan karakter sama dengan kepribadian. Kepribadian dianggap sebagai ciri, atau karakteristik, atau gaya, atau sifat khas dari diri seseorang yang bersumber dari bentukan-bentukan yang diterima dari lingkungan, misalnya lingkungan keluarga pada masa kecil dan juga bawaan seseorang sejak lahir. Karakter bangsa sebagai kondisi watak yang merupakan identitas bangsa. Dengan demikian, pendidikan membangun karakter, secara implisit mengandung arti membangun sifat atau pola perilaku yang didasari atau berkaitan dengan dimensi moral yang positif atau baik.

Muatan pendidikan karakter secara psikologis mencakup dimensi moral reasoning, moral feeling, dan moral behaviour (Lickona, 1992) atau dalam arti utuh sebagai morality yang mencakup moral judgment and moral behaviour baik yang bersifat prohibition-oriented morality maupun pro-social morality (Piaget, 1967; Kohlberg; 1975). Tanpa ketiga aspek ini maka pendidikan karakter tidak akan efektif, karena dengan pendidikan karakter, seorang anak akan menjadi cerdas emosinya. Kecerdasan emosi adalah bekal terpenting dalam mempersiapkan anak menyongsong masa depan. Pendidikan karakter JPSI, Vol. 1, No., 1, 2018 
merupakan pendidikan yang bertujuan untuk meningkatkan mutu penyelenggaraan dan hasil pendidikan yang mengarah pada pembentukan karakter dan akhlak secara utuh, terpadu, dan seimbang.

Lima pilar karakter luhur bangsa Indonesia tercermin dalam Pancasila adalah sebagai berikut (a). Transendensiyakni menyadari bahwa manusia merupakan ciptaan Tuhan Yang Maha Esa, (b). Humanisasi setiap manusia pada hakikatnya setara di mata Tuhan kecuali ilmu dan ketakwaan yang membedakannya. Kemanusiaan yang adil dan beradap, (c). Kebinekaan: kesadaran akan adanya sekian banyak perbedaan di dunia. Akan tetapi, mampu mengambil kesamaan untuk menumbuhkan kekuatan, Persatuan Indonesia, (d). Liberasi yakni pembebasan atas penindasan sesama manusia. Kerakyatan yang dipimpin oleh hikmah kebijaksanaan dalam permusyawaratan perwakilan dan (e). Keadilan: keadilan merupakan kunci kesejahteraan. Adil tidak berarti sama, tetapi proporsional. Keadilan sosial bagi seluruh rakyat Indonesia.

Sukamto (2007), sebagaimana dikutip Agus Dono Karmadi,2007) mengemukakan bahwa untuk melakukan pendidikan karakter, perlu adanya powerfull ideas, yang menjadi pintu masuk pendidikan karakter. Powerfull ideas ini meliputi: (a) god, the world dan me (gagasan tentang Tuhan, dunia, dan saya); (b) knowing yourself (memahami diri sendiri); (c) becoming a moral person (menjadi manusia bermoral); (d) understanding and being understood getting along with others (memahami dan dipahami); (e) a sense of belonging (bekerjasama dengan orang lain); (f) drawing strength from the past (mengambil kekuatan di masa lalu); (g) dien for all times dan places; (h) caring for Allah's creation (kepedulian terhadap makhluk); (j) making a difference (membuat perbedaan); dan (k) taking the lead ( memimpin)

Pendidikan karakter sebagai jantung pendidikan nasional sudah dimulai pada tahun 2010, ketika pemerintah mencanangkan sekaligus melaksanakan kebijakan Gerakan Nasional Pendidikan Karakter berlandaskan Rencana Aksi Nasional (RAN) Pendidikan Karakter Bangsadengan delapan belas (18) nilai karakter. Sebagai tindak lanjut dari RANPendidikan Karakter Bangsa, pemerintahdalam hal ini Kemendikbud melaksanakan Gerakan Penguatan Pendidikan Karakter (PPK) dengan mengindahkan asas keberlanjutan dan kesinambungan. Gerakan PPK menempati kedudukan fundamental dan strategis pada saat pemerintah mencanangkan revolusi karakter bangsa sebagaimana tertuang dalam Nawacita. ( Kemendikbud, Konsep Pedoman Penguatan Pendidikan Karakter untuk Pendidikan Dasar dan Menengah, 2017)

Gerakan PPK perlu mengintegrasikan, memperdalam, memperluas, dan sekaligus menyelaraskan berbagai program dan kegiatan pendidikan karakter yang sudah dil- 
aksanakan sampai sekarang. Dalam hubungan ini pengintegrasian meliputi sebagai berikut;(a) Pemaduan kegiatan kelas, luar kelas di sekolah, dan luar sekolah (masyarakat/komunitas). (b) Pemaduan kegiatan intrakurikuler, kokurikuler, dan ekstrakurikuler. (c) Pelibatan secara serempak warga sekolah, keluarga, dan masyarakat; (d) Perdalaman dan perluasan dapat berupa penambahan dan pengintensifan kegiatan-kegiatan yang berorientasi pada pengembangan karakter siswa, penambahan dan pemajanan kegiatan belajar siswa, dan pengaturan ulang waktu belajar siswa di sekolah atau luar sekolah. (e) Penyelerasan dan penyesuaian degan tugas pokok guru, Manajemen Berbasis Sekolah, dan fungsi Komite Sekolah dengan kebutuhan Gerakan PPK.

Ada lima nilai utama karakter yang saling berkaitan membentuk jejaring nilai yang perlu dikembangkan sebagai prioritas Gerakan PPK. Kelima nilai utama karakter bangsa yang dimaksud adalah sebagai berikut.

1. Religius: Nilai karakter religius ini meliputi tiga dimensi relasi sekaligus, yaitu hubungan ndividu dengan Tuhan, individu dengan sesama, dan individu dengan alam semesta (lingkungan). Nilai karakter religius ini ditunjukkan dalam perilaku mencintai dan menjaga keutuhan ciptaan.

2. Nasionalis : Nilai karakter nasionalis merupakan cara berpikir, bersikap, dan berbuat yangenunjukkan kesetiaan, kepedulian, dan penghargaan yang tinggi terhadap bahasa, lingkungan fisik, sosial, budaya, ekonomi, dan politik bangsa, menempatkan kepentingan bangsa dan negara di atas kepentingan diri dan kelompoknya. .

3. Mandiri: Nilai karakter mandiri merupakan sikap dan perilaku tidak bergantung pada orang lain dan mempergunakan segala tenaga, pikiran, waktu untuk merealisasikan harapan, mimpi dan cita-cita.

4. Gotong Royong : Nilai karakter gotong royong mencerminkan tindakan menghargai semangat kerja sama dan bahu membahu menyelesaikan persoalan bersama, menjalin komunikasi dan persahabatan, memberi bantuan/ pertolongan pada orangorang yang membutuhkan.

5. Integritas : Nilai karakter integritas merupakan nilai yang mendasari perilaku yang didasarkan pada upaya menjadikan dirinya sebagai orang yang selalu dapat dipercaya dalam perkataan, tindakan, dan pekerjaan, memiliki komitmen dan kesetiaan pada nilai-nilai kemanusiaan dan moral (integritas moral).

Kelima nilai utama karakter bukanlah nilai yang berdiri dan berkembang sendirisendiri melainkan nilai yang berinteraksi satu sama lain, yang berkembang secara dinamis dan membentuk keutuhan pribadi. Sedang prinsip-Prinsip Pengembangan dan Implementasi PPK menggunakan prinsip-prinsip sebagai berikut. a) Nilai-nilai Moral Universal; 
b) Holistik; c) Terintegrasi. d) Partisipatif; (e) Kearifan Lokal; 6) Kecakapan Abad XXI; f) Adil dan Inklusif; g) Selaras dengan Perkembangan peserta didik; dan 9) Terukur.

Gerakan PPK berfokus pada struktur yang sudah ada dalam sistem pendidikan nasional. Terdapat tiga struktur yang dapat digunakan sebagai wahana untuk memperkuat pendidikan karakter. Pertama, struktur Program, antara lain jenjang dan kelas, ekosistem sekolah, penguatan kapasitas guru. Kedua, Struktur Kurikulum, antara lain kegiatan pembentukan karakter yang terintegrasi dalam pembelajaran(intrakurikuler), kokurikuler, dan ekstrakurikuler. Ketiga, Struktur Kegiatan, antara lainberbagai program dan kegiatan yang mampu mensinergikan empat dimensi pengolahan karakter dari Ki Hadjar Dewantara (olah raga, olah pikir, olah rasa, dan olah hati).

\section{Pantulan Budaya Lokal “ Makna Filosofis dan Simbolisme Motif Batik Klasik' untuk Penguatan Karakter}

Kebudayaan dan pendidikan memiliki hubungan timbal balik sebab keberlanjutan kebudayaan dapat diwariskan melalui pendidikan, sebaliknya bentuk dan pelaksanaan pendidikan ikut ditentukan oleh kebudayaan masyarakat (Tirtarahardja dan Sulo, 2005). Pendidikan di sekolah seharusnya mencerminkan struktur sosial dan budaya masyarakat. Sebagaimana dikutip John Singleton (1974) diketahui bahwa budaya dalam konsep esensial pendidikan sebagai "the shared product of human learning", bahwa proses belajar tidak bisa dipisahkan dengan kehidupan manusia dalam rangka penciptaan budaya sekaligus pewarisannya (cultural creation and cultural transmission). Ada interelasi pendidikan dengan kebudayaan dalam arti pertumbuhan yang satu harus diimbangi dengan pertumbuhan yang lainnya, yang diharapkan memiliki potensi saling dukung (crossfertilizing) dalam rangka meningkatkan harkat dan martabat manusia. Seperti dijelaskan oleh Ki Hadjar Dewantara (1977) bahwa manusia akan benar-benar menjadi manusia kalau ia hidup dalam budayanya sendiri. Pendidikan adalah bagian dari proses manusia membangun dunia atau kebudayaannya.

Nilai budaya yang berasal dari motif batik klasik pada dasarnya bersumber dari ethos dan estetika serta aspek pandangan hidup dari priyayi Jawa. Priyayi menekankan perlunya sikap hormat kepada keteraturan hirarkis sebagai langkah awal dalam perjalanan manusia kepada Tuhan. Keteraturan hirarkis ini bernilai kepada dirinya sendiri dan oleh karena itu orang wajib mempertahankannya dan menempatkan diri sesuai dengan tempatnya. Dengan demikian akan tercipta masyarakat sebagai suatu kesatuan yang selaras sesuai tuntutan tata krama sosial.

Untuk itu dalam konteks masyarakat Jawa dikembangkan tiga perasaan yang harus dipelajari yaitu, wedi, isin, dan sungkan. Sedang untuk mencapai keselarasan hidup 
bermasyarakat ditentukan oleh dua prinsip dasar yakni rukun dan hormat (Suseno,1991). Prinsip rukun bertujuan untuk mempertahankan masyarakat dalam keadaan yang harmonis. Prinsip hormat berdasarkan hubungan dalam masyarakat yang teratur secara hirarkis. Keteraturan hirarkis ini bernilai kepada dirinya sendiri dan oleh karena itu orang wajib mempertahankannya dan menempatkan diri sesuai dengannya. Dengan demikian menjaga seluruh masyarakat, sebagai suatu kesatuan yang selaras merupakan tututan tata krama sosial. Manusia yang berhasil mengatur perilakunya sesuai tatakrama social akan mencapai keseimbangan batin. Transformasi nilai-nilai budaya priayi dalam motifmotif batik klasik juga berdasar pada tatanan (hirarkhi dan harmonisasi) dan tuntunan, ditunjukkan dalam bagan sebagai berikut.

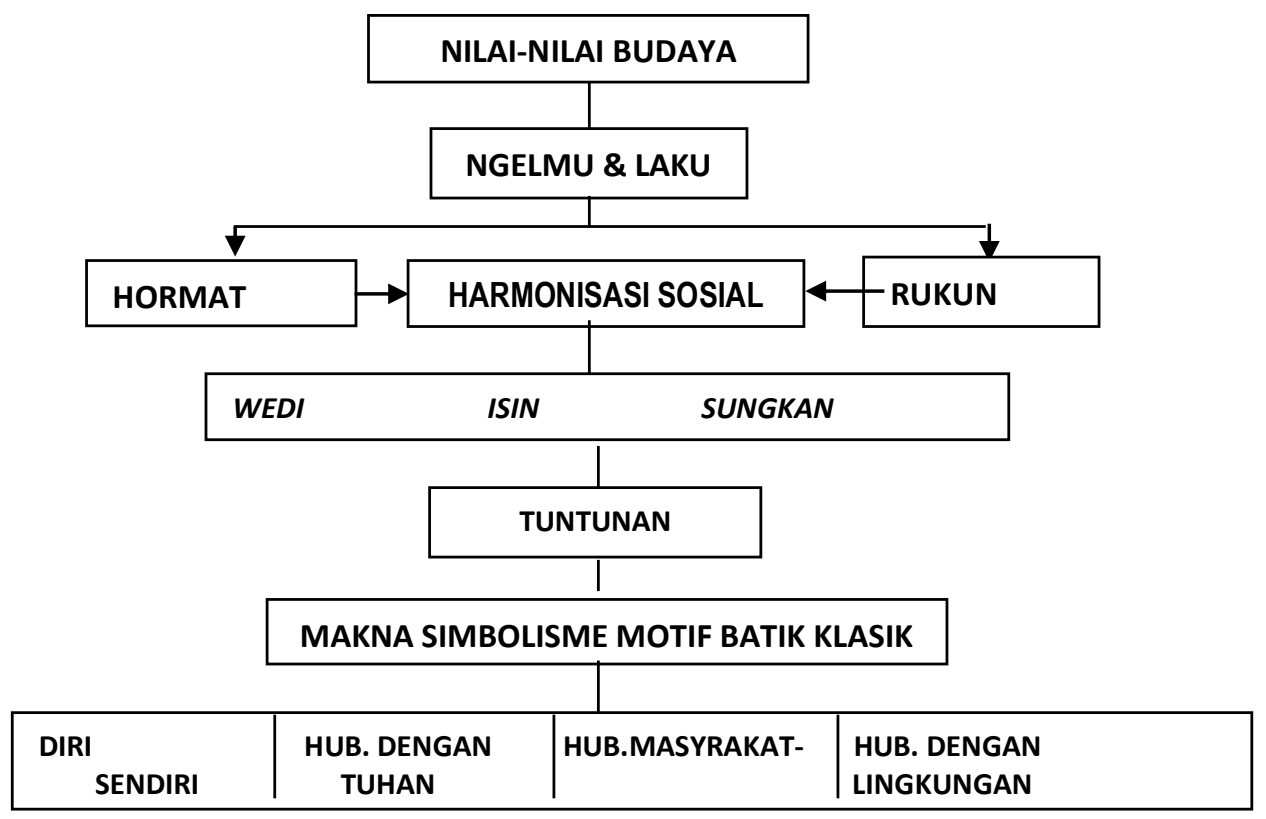

\section{Bagan 1.Transformasi Nilai Budaya Priyayi dalam Motif Batik Klasik (sumber: Sariyatun,2012)}

Dari bagan tersebut dapat dijelaskan bahwa motif batik klasik bukan hanya sebuah realitas fisik tetapi sebuah bentuk dari hasil pemikiran yang bersifat kolektif yang menunjukkan adanya kompleksitas idea-idea yang tersembunyi dalam simbolisme. Internalisasi nilai karakter berbasis nilai budaya batik klasik dapat direalisasikan dalam pembelajaran di sekolah terutama yang berkaitan dengan : a) Ideologi; disiplin, hukum dan tata tertib, mencintai tanah air, demokrasi, berani, setia kawan/solidaritas, rasa kebangsaan, patriotik, warga negara produktif, martabat/harga diri, setia/bela negara, b) Agama; iman kepada Tuhan Yang Maha Esa, taat pada perintah Tuhan cinta agama, patuh pada ajaran agama, berakhlak, berbuat kebajikan, suka menolong dan bermanfaat bagi 
orang lain, berdoa dan bertawakal, peduli terhadap sesama, berperikemanusiaan, adil, bermoral dan bijaksana, c) Budaya; toleransi dan itikad baik, baik hati, empati, tata cara dan etiket, sopan santun, bahagia/gembira, sehat, dermawan, persahabatan, pengakuan, menghormati, berterima kasih.

Dalam konteks keindonesiaan pendidikan karakter adalah proses menyaturasakan sistem nilai kemanusiaan dan nilai-nilai budaya Indonesia dalam dinamika kehidupan bermasyarakat, berbangsa, dan bernegara. Pendidikan karakter bangsa merupakan suatu proses pembudayaan dan transformasi nilai-nilai kemanusiaan dan nilai-nilai budaya bangsa (Batik Klasik) untuk melahirkan insan atau warga negara yang berperadaban tinggi, warga negara yang berkarakter. Sebagaimana dikemukakan Parkay and Stanford (1998) mengemukakan kaitan antara pembelajaran nilai dan moral dengan pendidikan karakter sebagi berikut." One approach to teaching values and moral reasoning is known as character education, a movement that stresses a development of students "good character".

Karakterisasi adalah proses internalisasi nilai yang telah mencapai tingkatan paling tinggi atau paling dalam. Penghayatan suatu nilai jika telah sampai pada tingkatan yang sangat dalam, maka nilai itu telah mengkarakter atau menjadi penanda khas kepribadian orang yang bersangkutan. Untuk memperjelas pembahasan ini, akan dipetakan relevansi makna filosofis dan simbolisme motif batik klasik dengan nilai utama karakter, yakni religius, nasionalis, mandiri, gotong royong dan integritas (terlampir).

\section{SIMPULAN}

Kearifan lokal memiliki peran yang penting dalam mengubah produk global menjadi bermakna dan sesuai dengan kehidupan sosial budaya setempat. Pendidikan berbasis pada kearifan budaya lokal secara proaktif mampu menghadapi tantangan globalisasi. Kearifan lokal, sebagai "tradisi yang ditemukan" menunjukkan bahwa kebudayaan masa lalu tidak benar-benar ditinggalkan meskipun zaman sudah berubah.

Keindahan pola hias batik dapat dilihat dari keindahan visual dan keindahan filosofis. Setiap penciptaan motif batik selalu memiliki makna simbolis berdasarkan falsafah Jawa, karena itu pemakaian motif didasarkan pada dua hal, yakni (1) kedudukan sosial seseorang di dalam masyarakat, (2) pada kesempatan atau peristiwa apa batik dipergunakan tergantung dari makna dan harapan yang terkandung pada ragam hias batik tersebut. Hal ini menjadikan Batik klasik mengandung tuntunan dan tatanan.Pemaknaan ulang secara dinamis atas core valuesmakna simbolisme motif batik dilakukan dengan konteks kekinian untuk kepentingan pendidikan.Batik klasik sebagai hasil budaya elite 
feodal (Kraton), merupakan media hegemoni budaya Kraton terhadap budaya rakyat. didekonstruksi untuk kepentingan penguatan pendidikan karakter.Implementasi pendidikan karakter berbasis kearifan local batik klasik dapat dilakukan melalui struktur kurikulum maupun kegiatan atau budaya sekolah.

\section{RUJUKAN}

Abdullah, Irwan. 2009. Kontruksi dan Reproduksi Kebudayaan. Pustaka Pelajar: Yogyakarta

Bastomi Suwasdji 1992. Seni dan Budaya Jawa. Semarang: IKIP Semarang.

Derrida, Jacques . 2001. Writing and Difference, Translated, with an introduction and additional notes, by Alan Bass, London :Routledge.

Dewantara, Ki Hajar. 1977. Karya Ki Hajar Dewantara. Bagian Pertama: Pendidikan.Yogjakarta: Penerbitan Taman Siswa.

Geertz, C. 1973. The Interpretation of Culture .New York: Basic Books.

Koesoema, A. 2010. Pendidikan Karakter. Jakarta: Grasindo.

Lickona, T. 1992. Educating for Character: How Our Schools can Teach Respect and Responsibility. New York: Bantam Books.

Lickona, Thomas., ed. 1976. Moral Development and Behavior: Theory; Research and Social Issues. New York: Copyright by Holt, Rinehart and Winston.

Parkay, Forrest W. and Beverly Hardcastle Stanford. 1998. Becoming A Teacher. BostonSingapore: Allen and Bacon.

Piaget, J. 1977. The development of thought: Equilibrium of cognitive structures. New York: Viking.

Sariyatun. 2011. "Social Studies Learning Model in Local Batik Klasik Cultural Based for the nation Identity Reinforcement of Junior High School Students'. Historia International Journal of History Education Vol XII No2 (Desember 2011) ISSN 20863276.

Sumaryono, E. 1999. Hermeneutik, Sebuah Metode Filsafat. Yogyakarta: Kanisius.

Suseno, Franz Magnis. 1996. Etika Jawa, Sebuah Analisa falsafi tentang Kebijaksanaan Hidup Jawa, Jakarta: PT Gramedia Pustaka Utama.

Watson, James L. 2004. Globalization in Asia: Anthropological Perspectives in theNew Millennium (ed) Marcelo M. Suárez-Orozco and Desirée Baolian Qin-Hilliard University of California Press Berkeley and Los Angeles, California 


\section{LAMPIRAN :}

Contoh pantulan budaya lokal "Makna Filosofis dan Simbolisme Motif Batik Klasik" sebagai Penguatan Karakter.

Tabel 1. Makna Filosofi Motif Batik Klasik Relevansinya dengan Karakter (Sumber : Sariyatun ,2012)

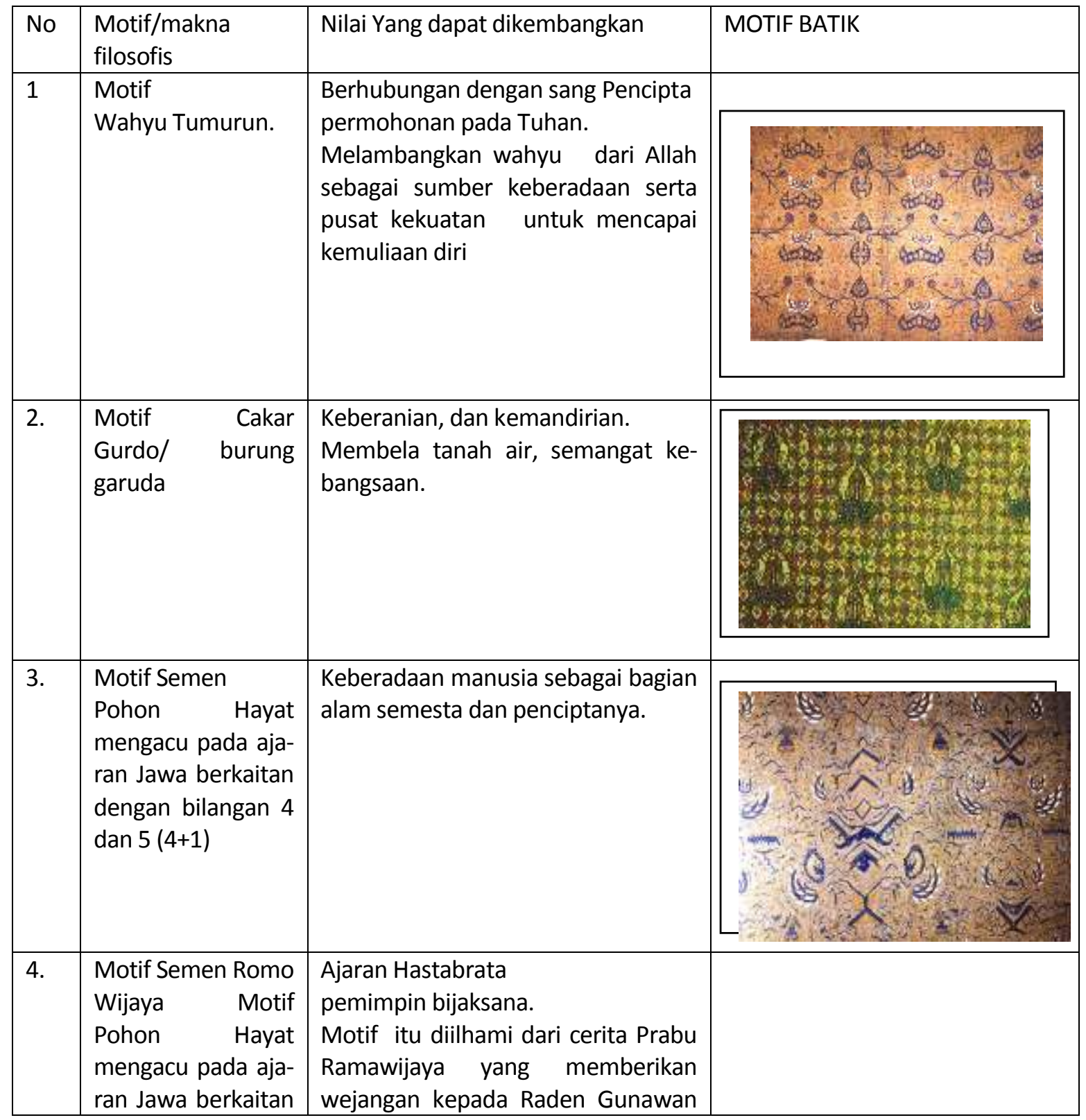

JPSI, Vol. 1, No., 1, 2018 


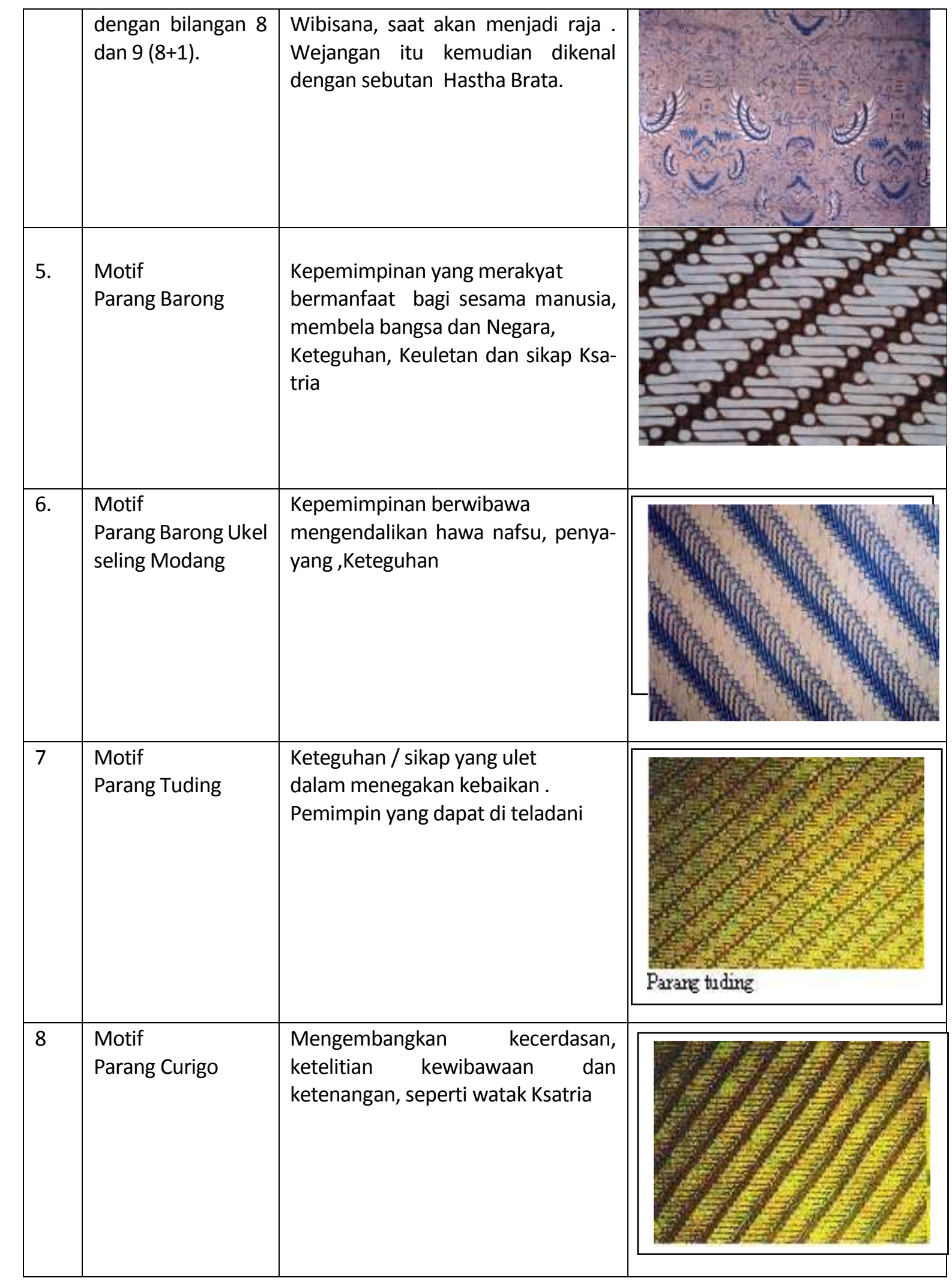

JPSI, Vol. 1, No., 1, 2018 


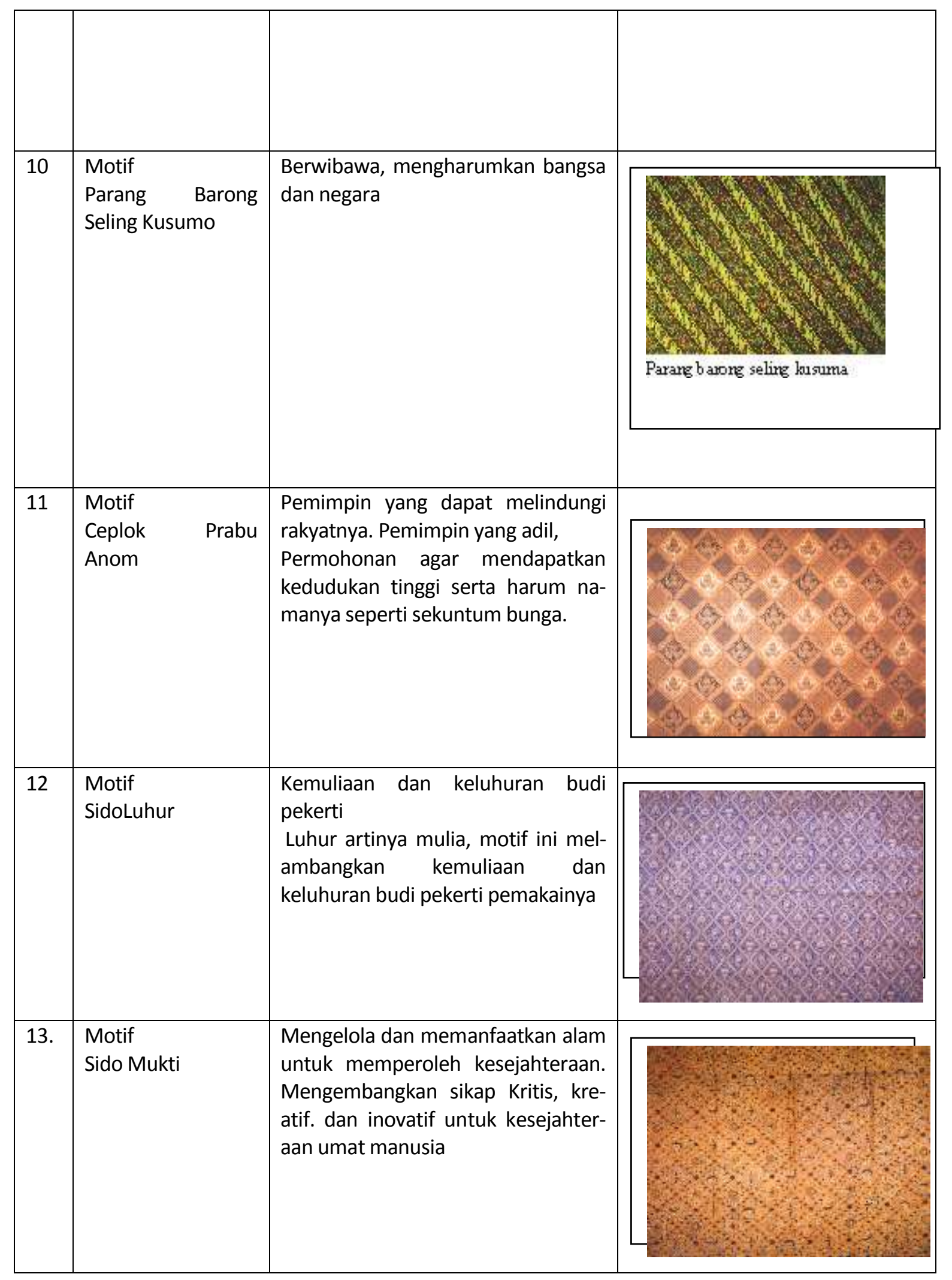

JPSI, Vol. 1, No., 1, 2018 


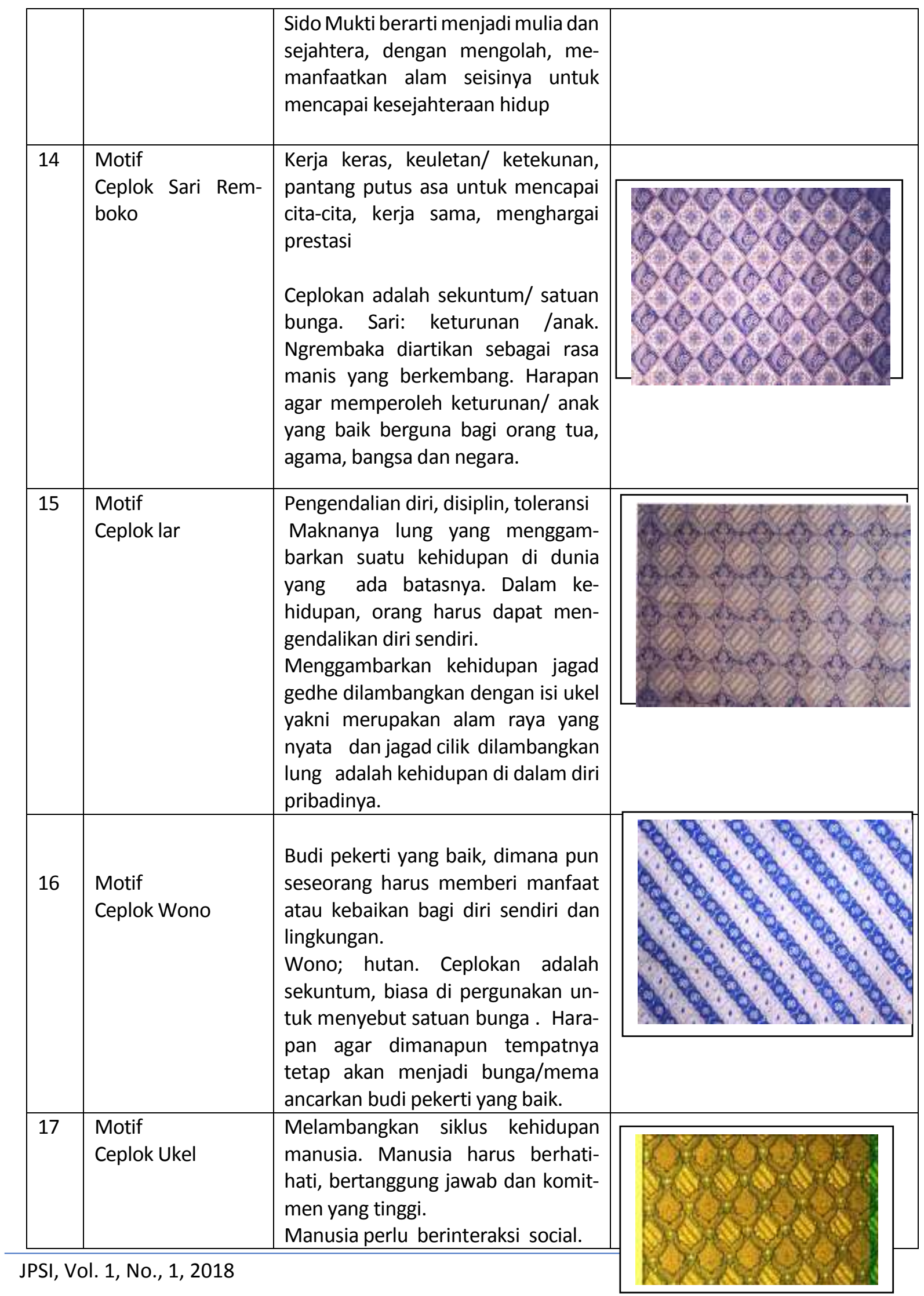




\begin{tabular}{|l|l|l|l|}
\hline & & $\begin{array}{l}\text { Ukel yakni corak yang melingkar kecil } \\
\text { menunjukkan siklus kehidupan } \\
\text { manusia bagaikan lingkaran. } \\
\text { Untuk dapat menjadi seorang ratu } \\
\text { atau raja, diperlukan dukungan dari } \\
\text { berbagai pihak. }\end{array}$ \\
\hline 18 & $\begin{array}{l}\text { Motif } \\
\text { Delimo mulyo }\end{array}$ & $\begin{array}{l}\text { Suka menolong. } \\
\text { bermanfaat bagi orang lain, } \\
\text { masyarakat bangsanya, } \\
\text { Delimo adalah buah khas daerah tro- } \\
\text { pis, berisi biji-biji kecil dalam jumlah } \\
\text { banyak dengan daging biji bening be- } \\
\text { rasa asam manis. Buah ini biasa dipa- } \\
\text { kai sebagai pencuci mulut dan untuk } \\
\text { obat penyakit dalam. }\end{array}$ \\
\hline
\end{tabular}

